\title{
Ontogeny of Neurotransmitter Systems in the Paracervical Ganglion and Uterine Cervix of the Rat
}

\author{
KELLI A. SULLIVAN, HAROLD H. TRAURIG, AND RAYMOND E. PAPKA \\ Department of Neurology, University of Michigan, Ann Arbor, Michigan (K.A.S.); \\ Department of Anatomy and Neurobiology, University of Kentucky Medical Center, \\ Lexington, Kentucky (H.H.T.); and Department of Anatomical Sciences, University of \\ Oklahoma Health Sciences Center, Oklahoma City, Oklahoma (R.E.P.)
}

\begin{abstract}
Background: The paracervical ganglia (PG) are components of the pelvic plexus that provides sensory and motor innervation to the reproductive system of the female rat. Several neurotransmitters including norepinephrine (NE), acetylcholine (ACh), neuropeptide Y (NPY), and vasoactive intestinal polypeptide (VIP) are present in neurons of the adult $P G$ and in axons innervating the adult uterus and uterine cervix. The current study was undertaken to describe the onset of immunoreactivity of these neurotransmitters and neuropeptides during development.

Methods: Female rats, ages E18 to P36, were prepared for immunohistochemistry for TH (tyrosine hydroxylase, a marker of noradrenergic neurons), NPY, or VIP as well as the histochemical demonstration of acetylcholinesterase (AChE).

Results: All four markers were detected in neurons of the PG at E18. Changes in the appearance of these markers from E18 to P36 reflected previously described growth changes in the PG. Axons containing AChE, TH, NPY, or VIP were first detected within the cervix at E20. Immunopositive axons first appeared as thick, unbranched structures at the outermost portion of the cervical myometrium. Over time, these axon bundles ramified to form discrete varicose axons. The ingrowth was similar for axons containing each of the four markers.

Conclusions: The relative density of each neuronal type in the PG was reflected in the density of axons containing the same marker in the cervix. Changes in neurotransmitter/neuropeptide staining of PG neurons or axons in the cervix were not observed as the animals approached puberty. (c) 1994 Wiley-Liss, Inc.
\end{abstract}

Key words: Paracervical ganglia, NPY, VIP, TH, AChE, Development, Cervix, Rat

The innervation of the female reproductive system in the rat is derived from multiple sources including sensory neurons located in the lumbosacral dorsal root ganglia and sympathetic and parasympathetic neurons of the sympathetic chain and PG (Baljet and Drukker, 1980; Nadelhaft and Booth, 1984; Nadelhaft and Vera, 1991; Papka and Traurig, 1993). The PG are important components of the pelvic plexus (Langworthy, 1966; Mustonen and Teravainen, 1971; Baljet and Drukker, 1980; Sato et al., 1989; Nadelhaft and Vera, 1991). Both the hypogastric and pelvic nerves project through, and synapse with, the principal neurons of the PG which in turn project axons that join the pelvic plexus (Purinton et al., 1973; Baljet and Drukker, 1980; Papka et al., 1985; Papka and Traurig, 1993). Functional studies show that uterine innervation plays a role in the maintenance of pregnancy and partuition. In the rat, a particular class of uterine cervical sensory nerves forms the afferent limb of the neuroendocrine copulatory luteal response that is obligatory for fertility (Carlson and DeFeo, 1965; Adler et al., 1970; Traurig et al., 1984; Cunningham et al., 1992).

A number of studies have described the neurochemical anatomy of the adult rat $P G$ and uterine cervix. Acetylcholine $(\mathrm{ACh})$, norepinephrine (NE), neuropeptide Y (NPY), and vasoactive intestinal polypeptide (VIP) have been reported in principal neurons of the $\mathrm{PG}$ and in axons innervating the uterine cervix (Shabanah et al., 1964a,b; Adham and Schenk, 1969; Kanerva, 1971; Kanerva 1972a,b; Alm et al., 1980; Allen et al., 1985; Inyama et al., 1985; Papka et al. 1987). In addition to principal neurons, the PG also contains

Received March 8, 1994; accepted May 12, 1994.

Dr. Kelli A. Sullivan, Dept. Neurology, University of Michigan, Kresge III, Room 4414, Ann Arbor MI 48109. 
small intensely fluorescent (SIF) cells (Kanerva, 1972a; Baker et al., 1977; Papka et al., 1987). The SIF cells of the PG are similar to those described in other autonomic ganglia and contain a primary catecholamine as well as neuropeptides (Dail et al., 1975; Partanen et al., 1980; Papka et al., 1987). Axons containing NE, ACh, NPY, and VIP have been reported to innervate the myometrium as well as the blood vessels supplying the reproductive organs (Hervonen et al., 1973; Alm et al., 1980; Allen et al., 1985; Papka et al., 1985; Brauer et al., 1992).

The ultrastructural characteristics of the PG as well as the developmental appearance of norepinephrine (NE, as studied by catecholamine fluorescence) and acetylcholine (ACh, as studied by acetylcholinesterase histochemistry) have been investigated in neurons of the postnatal, prepubertal rat (Kanerva, 1971), but little attention has been directed to the ontogeny of other neurotransmitter substances in the PG. Also, few developmental studies concerning the onset of peptidergic innervation of female reproductive organs are available. The present study was undertaken to examine the pre- and post-natal emergence of tyrosine hydroxylase-immunoreactivity ( $\mathrm{TH}$, a marker of noradrenergic neurons), acetylcholinesterase (AChE, an indirect marker of cholinergic neurons), and NPY-and VIP-immunoreactivity within principal neurons of the $P G$ and in axons innervating a target of the $P G$, the uterine cervix. This information will provide a baseline of the normal developmental progression of these markers and serve as a basis for further investigations of the developmental relationship between PG neurons and their targets and possible effects of the hormonal environment on this development.

\section{MATERIALS AND METHODS}

Adult female Sprague-Dawley rats (Harlan, Madison WI) were housed in the University of Kentucky Medical Center Vivarium (PHS assurance A33301) with free access to food and water and under a 14:10 light: dark cycle. Rats were mated to provide the fetal and prepubertal females used in this study. Vaginal lavages were performed each morning to determine if mating had occurred; the day sperm were observed in the vaginal lavage was counted as day 1 of pregnancy; the day of birth was designated as postnatal day 0 (P0).

The uterine cervix and PG were obtained from prenatal animals on embryonic days 18 and 20 (E18,E20) and from postnatal animals ages $0,1,2,5,8,16$, and 36 days (P0-P36). Four to ten animals were examined per time point. Pregnant dams were deeply anesthetized with ether prior to decapitation. Embryos were quickly dissected from the uterus and decapitated. Postnatal animals were also killed by decapitation. As an aid in locating the developing PG, animals at ages E18 to P5 were transversely sectioned through the pelvic region including the vertebral column, epaxial musculature, and gut as well as the cervix and PG. The cervix and $\mathrm{PG}$ were dissected from animals at P8 to P36. Tissue samples were immersed in Zamboni's fixative $(2 \%$ paraformaldehyde, $0.15 \%$ picric acid in phosphate buffer (Stephanini et al., 1967) at $4^{\circ} \mathrm{C}$ for 4 hours. After fixation, tissues were rinsed in several changes of 0.1 $\mathrm{M}$ phosphate buffer (pH 7.0) containing 5\% sucrose for cryoprotection.
Cryostat sections $(14 \mu \mathrm{m})$ were processed for histochemistry and immunohistochemistry. The sections were incubated at $22^{\circ} \mathrm{C}$ for 18 to 24 hours in primary antisera, rinsed with phosphate buffer and incubated with FITC conjugated sheep anti-rabbit IgG for 1 hour at $22^{\circ} \mathrm{C}$. Coverslips were mounted with phosphate buffered glycerol ( $\mathrm{pH} 8.6$ ).

Sources and dilutions of antisera used for immunohistochemistry are as follows: VIP (1:200 dilution) antiserum 7913, provided by Dr. J.H. Walsh (Furness et al., 1981); NPY (1:400 dilution) antiserum 102F, provided by Dr. Lars Terenius (Lundberg et al., 1983); and TH antisera (1:200 dilution) was obtained from Eugene Tech, Allendale, NJ. All antisera were raised in rabbits and have been previously characterized and used in studies in this laboratory (Furness et al., 1981; Lundberg et al., 1983; Papka et al., 1987; Papka and Traurig, 1988). For control purposes, sections were incubated with preabsorbed antisera $(10 \mu \mathrm{g}$ of peptide per $\mathrm{ml}$ antisera), primary antisera alone, or secondary antisera alone. In these control studies immunopositive cells and axons were not observed.

Sections were also processed for the histochemical demonstration of the enzyme AChE (El-Badawi and Schenk, 1967). These sections were thaw-mounted onto slides, rinsed in PBS, and incubated in a medium consisting of acetylthiocholine-iodide $(12.5 \mathrm{mg}), 0.06 \mathrm{~N} \mathrm{so-}$ dium acetate $(15.8 \mathrm{ml}), 0.1 \mathrm{~N}$ acetic acid $(0.5 \mathrm{ml}), 0.1 \mathrm{M}$ sodium citrate $(1.2 \mathrm{ml}), 30.0 \mathrm{mM}$ cupric sulfate $(2.5 \mathrm{ml})$, $4.0 \mathrm{mM}$ iso-OMPA (tetraisopropylpyrophosphoramide) $(0.5 \mathrm{ml}), 5.0 \mathrm{mM}$ potassium ferricyanide $(2.5 \mathrm{ml})$, and distilled water $(2.0 \mathrm{ml})$. This solution was prepared immediately prior to incubation. The sections were immersed in the medium and incubated at $37^{\circ} \mathrm{C}$ for 180 minutes then rinsed in PBS.

\section{RESULTS \\ $P G$}

At E18 the PG was clearly distinguished from the surrounding muscle and connective tissue. Immature principal neurons contained euchromatic nuclei with one or more nucleoli. Principal neurons were also characterized by an irregular outline suggestive of process outgrowth. SIF cells were comparable in size to the immature neurons but could be distinguished by their round shape and distribution as tight clusters. Satellite cells were also observed in the E18 PG. These cells contained heterochromatic nuclei and relatively little cytoplasm.

\section{AChE}

AChE reaction product formed a thin, dark rim around an unstained nucleus in neurons of the E18/ E20 PG (Fig. 1A). The amount of reaction product varied among neurons from a moderate amount of $\mathrm{AChE}$ to no reaction product. At $\mathrm{P} 5, \mathrm{AChE}$ reaction product often formed a "cap" occupying one side of the neuron (Fig 1B). Dense granules of $\mathrm{AChE}$ reaction product were associated with a subset of principal neurons (Fig. 1C). It was not clear if these granules represented cholinergic synaptic contacts or subcellular compartmentalization of the enzyme within the endoplasmic reticulum. The relative number of dense granules of $\mathrm{AChE}$ associated with the neurons increased by P8 and P16. At P36, the principal neurons of the PG were more 
mature as evidenced by increased neurite outgrowth; however, AChE reaction product was similar to previous ages (Fig. 1D).

\section{TH}

At E18/E20 and P0, two cell types contain TH-immunoreactivity (ir), the principal neurons and the SIF cells (Fig. 2A). TH-ir principal neurons and SIF cells were similar in size but could be distinguished from one another by the intensity of their fluorescence and distributions within the PG. The TH-ir of the principal neurons was moderate and confined to a narrow rim surrounding a non-fluorescent nucleus, while TH-ir of the SIF cells was more intense and in many cases obscured the morphology of the cell. Also, principal neurons were scattered as individual neurons or in small groups throughout the PG, while SIF cells occurred in clusters. From P5, TH-ir neurons and SIF cells could be distinguished on the basis of size as principal neurons were comparatively larger than SIF cells (Fig. 2B). Varicose TH-ir axons were detected within the PG at P5 and some TH-ir axons could be traced to their cell body of origin (Fig. 2B). As PG development progressed, the number of TH-ir neurons per section varied suggesting a compartmentalization of the TH-ir neurons within the PG. By P36, TH-ir neurons were occasionally observed in groups, more often, TH-ir neurons were few and appeared to comprise a small percentage of the total number of $\mathrm{PG}$ neurons at all developmental ages examined (Fig. 2C). TH-ir SIF cells were also detected within the PG on P36 and were similar to those previously described.

\section{NPYNIP}

The immunostaining of NPY and VIP within PG neurons was quite similar. At E18/E20, NPY-/VIP-ir neurons contained a conspicuous non-fluorescent nucleus surrounded by a narrow rim of fluorescent cytoplasm (Fig. 2D). From P1 to P36, two types of NPY-/ VIP-ir neurons were observed: 1) neurons with a homogeneous, fluorescent halo of immunoreactivity around a dark, non-fluorescent nucleus and 2) neurons with a perinuclear ring of granular fluorescence (Fig 2E). At P5, VIP-ir formed a perinuclear "cap" similar to that observed for AChE at the same age (Fig. 2F). At all ages examined, a large proportion of principal neurons contained some NPY-/VIP-ir.

\section{Cervix}

The pattern of axonal growth into the cervix was the same for axons containing AChE, TH, NPY, or VIP. Labeled nerve fibers were not observed in the E18 cervix. Labeled structures were first noted in the most peripheral portion of the cervix on E20. These "structures" were relatively thick and unbranched when compared to immunopositive axons at later developmental stages. As development progressed, the presumptive nerve trunks ramified and gave rise to smaller nerve bundles and finally to individual varicose axons. Nerve fibers were associated with smooth muscle fascicles of the myometrium as well as the blood vessels supplying the cervix.

\section{AChE/TH/NPY VIP}

Axons were not observed in the cervix on E18; however, on E20, presumptive axons were detected in the perimetrium. At P0, axon bundles appeared as thick, unbranched nerve trunks in the cervical perimetrium and outermost portion of the cervical myometrium (Fig. 3A). By P5, axons were more widely distributed within the cervical myometrium (Fig. 3B). Smaller nerve bundles were seen to branch from the larger nerve trunks; therefore, axon bundles of varying sizes were present on P5 and P8. By P16, axons had ramified further and thus appeared thinner. Also at this time, axons were detected throughout the cervical myometrium and near the endocervix. Individual varicose axons could be distinguished by P36 and were widely distributed throughout the cervix (Fig. 3C). Throughout development, axons were observed in close association with fascicles of smooth muscle and blood vessels (Fig. 3D). Axonal ingrowth paralleled, but was not confined to, the growth of blood vessels.

At the early developmental stages, E18-P5, AChEpositive, TH-, NPY-, and VIP-ir axons were about equally represented. At P16, fewer TH-ir nerve fibers were present per section of cervix than at earlier developmental stages. By P36, AChE-positive axons were in the majority followed by numerous NPY-and VIP-ir axons (Fig. 4A,B). TH-ir axons were relatively few and were most often associated with blood vessels rather than the myometrial smooth muscle (Fig. 4C). The relative number of AChE-positive and TH-, NPY-, and VIP-ir axons reflected the number of neurons labeled for these markers in the PG.

\section{DISCUSSION}

The present study provides the first description of the development of neurons containing NPY or VIP within the PG of prenatal and prepubertal rats. Immunoreactivity for these two peptides was evident in PG neurons at E18. The fluorescent immunostaining for these peptides ranged from moderate to intense and by P5/P8 often appeared granular. The granular character of NPY- or VIP-immunoreactivity coincides with the increase in neuronal size and suggests compartmentalization of these peptides within the Golgi complex and/or secretory granules (Gainer et al., 1977; Steiner et al., 1984).

The findings in this study concerning early neuronal morphology and subsequent maturation of $\mathrm{PG}$ neurons and SIF cells are in agreement with earlier reports regarding the $P G$ (Kanerva, 1971, 1972a). As the $P G$ matured, principal neurons increased in size, cytoplasmic volume and number of organelles and the neurons extended neurites (Kanerva, 1971, 1972a). While neuronal size was not measured in this study, an apparent increase was noted as well as an increase in the overall volume of the PG over time. Neurite extension was observed early in development, at E18, with varicose axons appearing at $\mathrm{P} 8$ and increasing in number up to P36.

The appearance of histochemical markers for neurotransmitter agents changed over time. AChE staining first appeared at E18 as a thin rim of light-brown precipitate around the nucleus. This staining became more intense with the increasing age of the animals, up 

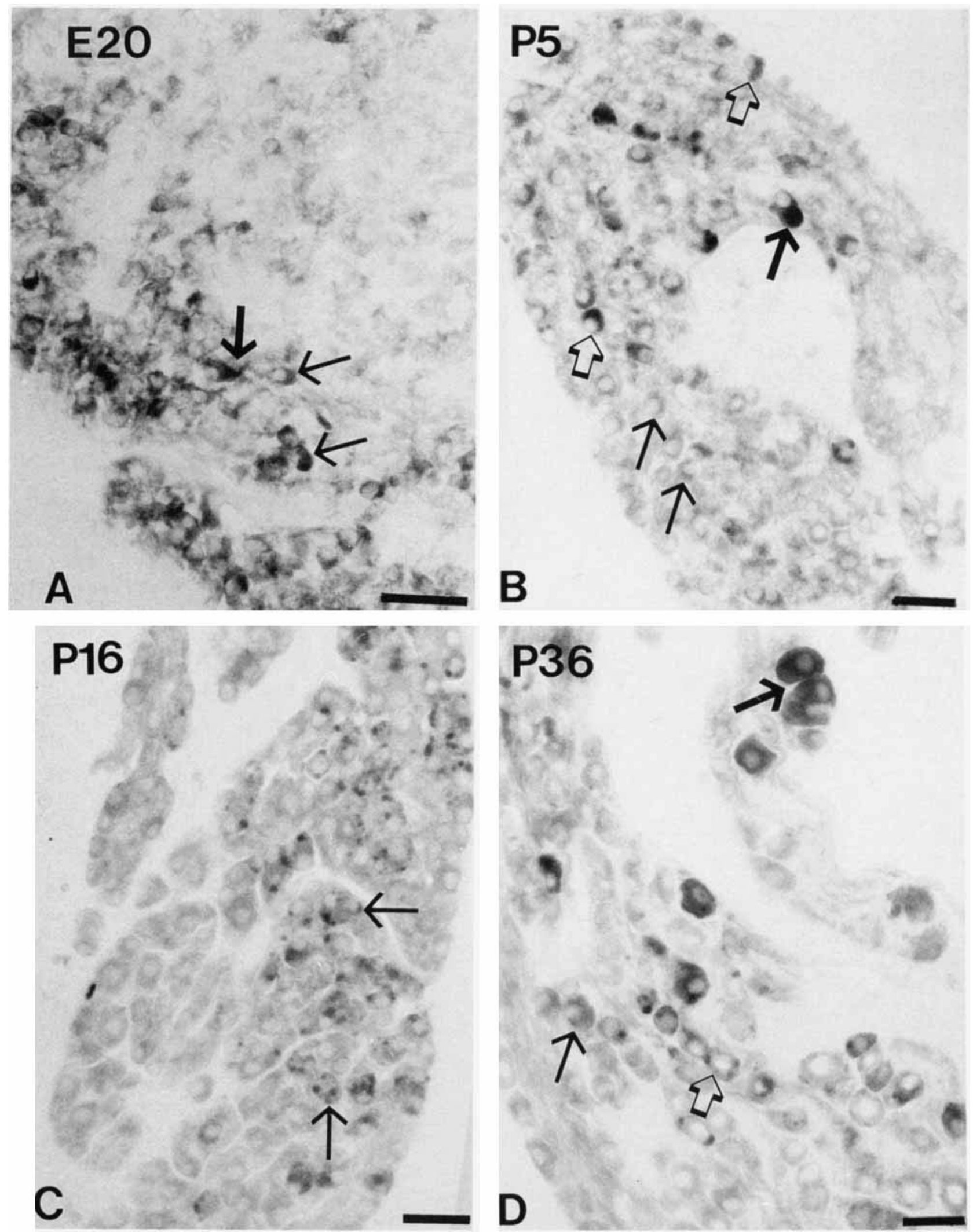

Fig. 1. A: AChE reaction product fills the cytoplasm of many PG neurons (thin arrows) at $\mathrm{E} 20$. Neurite outgrowth is apparent in some neurons (thick arrow). B: At P5, AChE staining ranges from intense (thick arrow) to moderate (thin arrows). In several PG neurons, AChE reaction product forms a perinuclear "cap" (open arrows). C: Dense

granules of $A C h E$ reaction product are often associated with $P G$ neurons (arrows). D: At P36, AChE reaction product ranges from intense (thick arrow) to moderate (thin arrow). Dense granules of AChE reaction product are detected in some principal neurons (open arrow). A) scale bar, $25 \mu \mathrm{m}$; B-D) scale bar, $50 \mu \mathrm{m}$. 

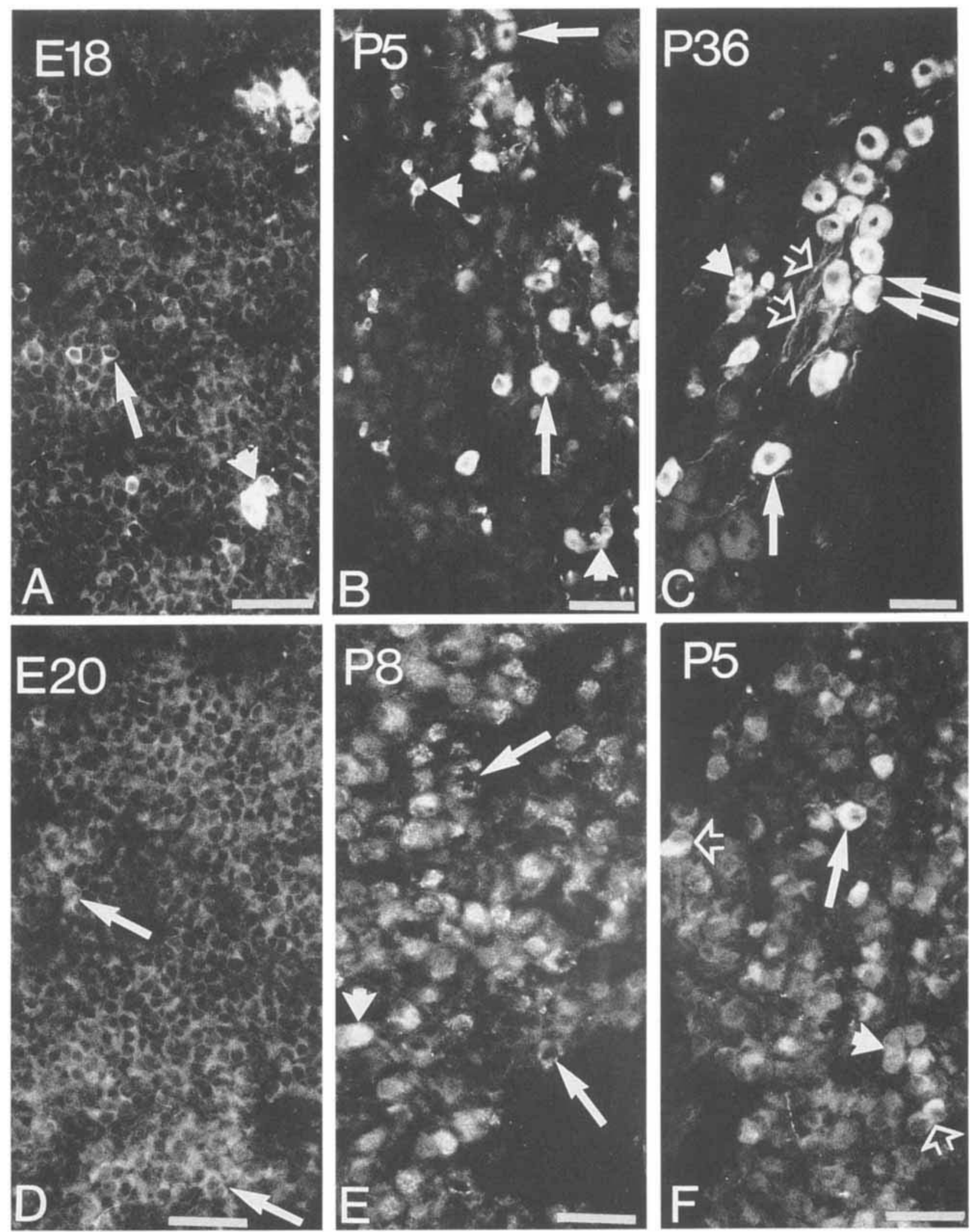

Fig. 2. A: Two cell types, principal neurons (arrow) and SIF cells (arrowhead) contain TH-ir at E18. B: By P5, TH-ir principal neurons (arrows) appear larger than the TH-ir SIF cells (arrowheads). C: In the PG at P36, TH-ir principal neurons are often observed in groups (arrows). TH-ir SIF cells (solid arrowhead) and TH-ir axons (open arrowheads) are also noted. D: At E20, a large proportion of PG neurons

contain NPY-ir (arrows). E: NPY-ir appears as a granular perinuclear ring (arrows) in some neurons or homogenous fluorescence (arrowhead). F: VIP-ir ranges from moderate (solid arrowhead) to intense (arrow) and forms a perinuclear "cap" (open arrowheads) in some neurons. Scale bars, $50 \mu \mathrm{m}$. 

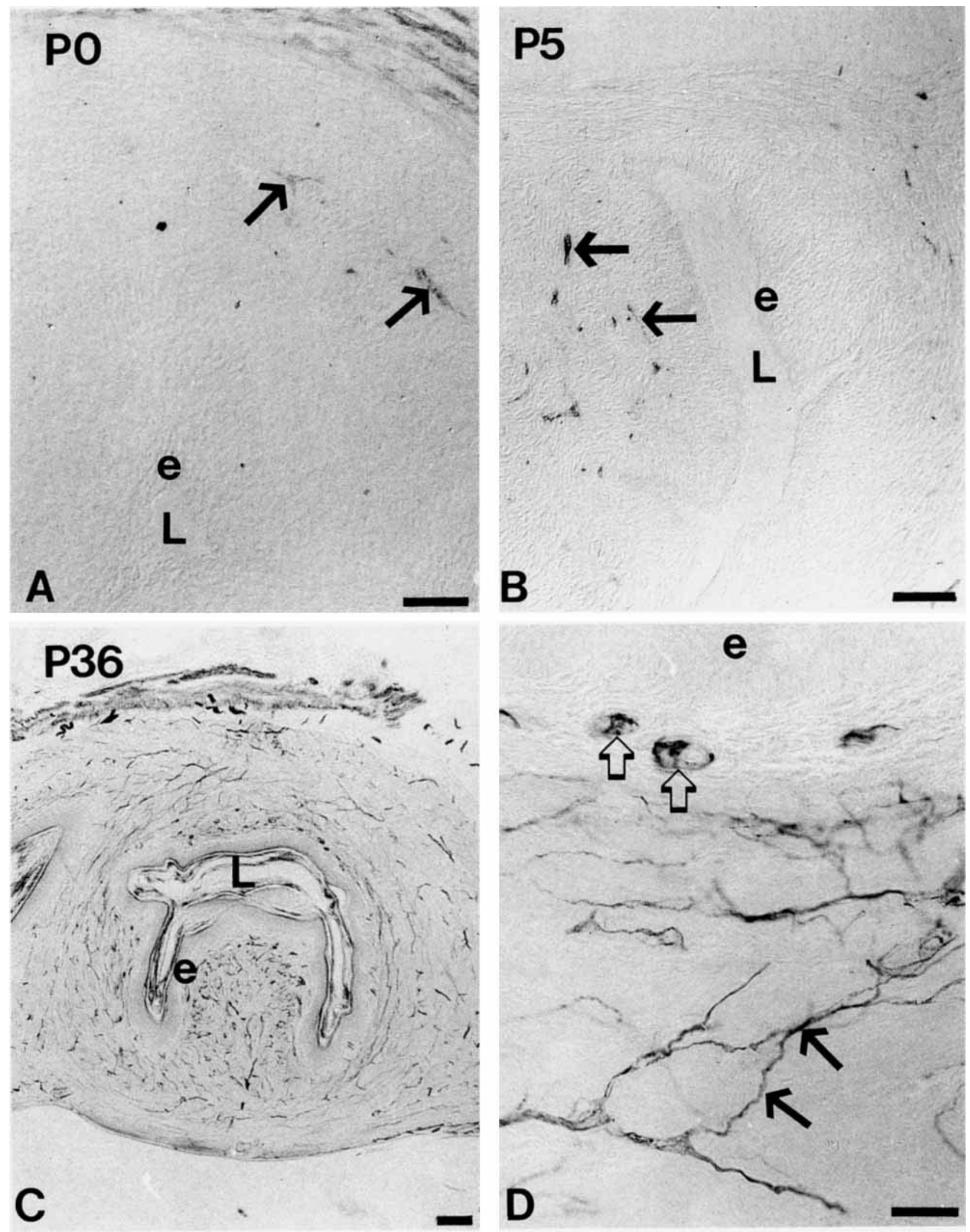

Fig. 3. A series of photomicrographs demonstrating AChE positive axonal growth into the uterine cervix. e, epithelium; L, lumen. A: At PO, axons are first detected in the outermost portion of the cervix (arrows). B: By P5, axons have distributed further into the cervix

(arrows). C: AChE-positive axons are widely distributed throughout the cervix at P36. D: AChE-positive axons (arrows) are associated with the smooth muscle of the cervix (arrows) and with blood vessels (open arrows). A,B,D) scale bar, $50 \mu \mathrm{m}$; C) scale bar, $200 \mu \mathrm{m}$. 

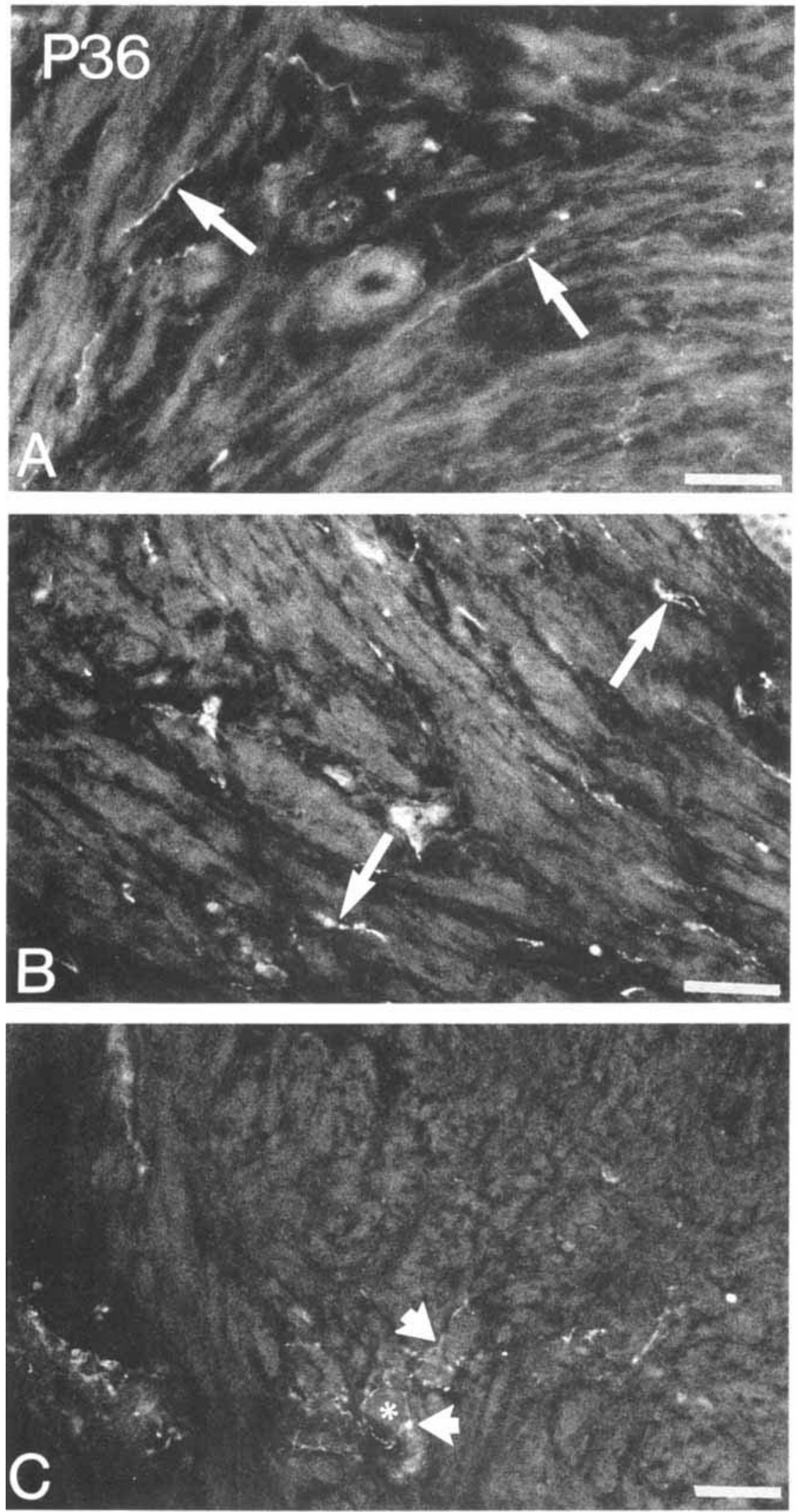

Fig. 4. The pattern of axonal ingrowth for both VIP-ir (A, arrows), NPY-ir ( $\mathbf{B}$, arrows), and TH-ir (C, arrowheads) axons is similar to that described for AChE. At P36, VIP- and NPY-ir axons are found throughout the cervix in close association with smooth muscle fascicles (A,B, arrows) while TH-ir axons (C, arrowheads) are most often observed innervating blood vessels (asterisk). Scale bar, $50 \mu \mathrm{m}$. 
to P36. Dense granules of $\mathrm{AChE}$ reaction product were associated with PG neurons by P5. These granules of reaction product were most often observed at the periphery of the principal neurons and possibly represent synaptic contacts from preganglionic cholinergic neurons. Synapses appear in the PG at P4 and their number increases over time (Kanerva, 1972b). Also, a "cholinergic nerve net" has been reported in the developing PG (Kanerva, 1972b) and nerve terminals with ultrastructural characteristics of cholinergic terminals (Mustonen and Teravainen, 1971; Kanerva and Teravainen, 1972; Papka and McNeill, 1992b) and containing AChE (Kanerva, 1971; Papka et al., 1987) are present in the adult PG.

TH-ir in two cell types of the developing PG ranged from intense to moderate, with $\mathrm{TH}$-ir cells occurring singly or in groups of 2-4 cells. On the basis of on the findings of Kanerva (1971) and the pattern of TH expression in the adult (Papka et al., 1987), it is likely that the more intensely TH-ir cells occurring in clusters are SIF cells and the more moderately TH-ir cells in small groups or found singly are principal neurons. It has been postulated that cells in fetal ganglia demonstrating catecholaminergic traits are precursors for both neurons and SIF cells (Papka, 1972, 1976; Molenaar et al., 1990; Hall and Landis, 1991a,b). By P5, the principal neurons have increased in size and attained distinguishing neuronal characteristics allowing their differentiation from TH-ir SIF cells.

AChE-positive neurons appeared to be the most numerous; in fact, the majority of PG neurons contained this marker at all developmental stages. In addition, NPY-ir neurons comprised over one-half of the neuronal population per section at each developmental stage whereas, approximately one third of the neurons were VIP-ir. TH-ir neurons were few throughout development. The relative numbers of AChE-positive, NPYir, VIP-ir, or TH-ir neurons in the developing PG coincide with the distribution of neuronal markers in the adult PG (Papka et al., 1987; Papka and Traurig, 1993). Recent preliminary cell counts indicate that more than $90 \%$ of the PG neurons are AChE-positive, about $60 \%$ are NPY-ir, $42 \%$ are VIP-ir, and approximately 6\% are TH-ir (Papka and Traurig, 1993). This is of special interest since the sum of these percentages totals over $100 \%$. Such data would indicate that some, if not all, PG neurons contain more than one neurotransmitter/neuropeptide. Presently, there is ample evidence to indicate that most, if not all, neurons contain more than one type of neurotransmitter or neuropeptide (Lundberg et al., 1982a,b; Heym et al., 1984; Blessing et al., 1986; Gibbins et al., 1987; Morris and Gibbins, 1987; Papka and Traurig, 1988; Keast, 1992; Papka and McNeill 1992). With regard to the PG, double immunostaining has indicated coexistence of markers for NPY/VIP, NPY/AChE, and VIP/AChE (Papka and Traurig, 1993) but cell counts of each neuronal phenotype will be required to establish patterns of coexistence of transmitter substances.

The findings of the present study concerning the development of the innervation of the uterine cervical myometrium, are consistent with a previous report of the development of $\mathrm{NE}$ axons in the rat uterus (Brauer et al., 1992) as well as other smooth-muscle containing tissues (Anderson and McLachlan, 1991; Hill et al.,
1991; Wadhwas et al., 1993). Structures containing AChE, TH, NPY, and VIP were first observed in the outermost portion of the cervical myometrium on P0. These "structures," even though rather large and poorly demarcated, are presumed to be growing axons. With increasing neonatal age, such "structures" appeared to ramify and give rise to the fine, discrete, varicose axons and terminals which innervate the cervical myometrium and blood vessels. The identification of these immunofluorescent "structures" as growing nerve fibers is further supported by the presence of GAP-43-immunoreactivity and synapsin I-immunoreactivity at the periphery of the uterine cervix on E20 (Papka, unpublished observations).

As development progresses, axons continued to ramify and distribute further within cervical myometrium. By P36, axons are of a similar morphology and distribution as those described in the adult cervix (Kanerva, 1972b; Alm et al., 1980; Ottesen et al., 1981; Stjernquist et al., 1983; Stjernquist et al., 1985; Gu et al., 1984; Stjernquist et al., 1984; Allen et al., 1985; Papka et al. 1985; Papka and Traurig, 1988). The relative densities of each axonal marker in the cervix reflects the abundance of that marker in the PG, i.e., AChEpositive axons are the most abundant followed by NPYir, VIP-ir, and TH-ir axons.

Neurons of the PG are immunopositive for neurotransmitters and neuropeptides on E18 as compared to $\mathrm{P} 0$, when these substances can be visualized within axons innervating the uterine cervix. It is possible that the cervix is innervated prior to P0 but the terminals contain insufficient concentrations of neurotransmitters and neuropeptides for detection by immunohistochemistry. The beginning of functional innervation of the cervix is as yet unknown. With regard to the myometrium, the physiological effects of neurotransmitters and neuropeptides have yet to be demonstrated in prepubertal animals. It would be of great interest to determine at what developmental stage all components necessary for neurally evoked muscle contractions are in place, e.g., nerve terminals containing neurotransmitters, receptors for neurotransmitters on the smooth muscle cells, and any effects the hormonal environment might have on this maturation. As previously stated, structures that appear to be axons containing neurotransmitters and neuropeptides are present in the cervix on P0; however, it is not yet known when receptors for these substances appear.

The adult PG of several species are reportedly responsive to the changing hormonal environment. For example, a subset of principal neurons, the vacuolated neurons, increase as a result of pregnancy, age and hormone treatment and are rarely seen in prepubertal animals (Takahashi 1960; Takahashi and Shimai, 1961; Partanen and Hervonen, 1979). Also, the PG and its equivalent ganglion in the male, the major pelvic ganglion (MPG), are sexually dimorphic with regard to cell number (Greenwood and Coggeshall 1985) and neurotransmitter type (Nadelhaft and Vera, 1991). While the hormonal environment of the female rat changes dramatically from birth to puberty (Weisz and Gonsalus, 1973; Dohler and Wuttke, 1975; Ojeda et al., 1975), changes in neurotransmitter appearance in the present study did not correlate with any known hormonal changes. 
In summary, neurons of the PG express neurotransmitters and neuropeptides early in development. Changes in the appearance of these substances reflect the developmental i.e., growth changes occurring in the ganglia. Axons containing these markers are not detected within their target until slightly later. Both the PG and the uterine cervix have reached an adult appearance by P36.

\section{ACKNOWLEDGMENTS}

The authors thank Dr. Lars Terenius and Dr. J.H. Walsh for their generous donation of antisera. This work was supported in part by BRSG RR05374 from the Biomedical Research Support Branch, Division of Research Facilities and Resources, NIH and by NIH grant 1 RO1 NS22526.

\section{LITERATURE CITED}

Adham, N. and E.A. Schenk 1969 Autonomic innervation of the rat vagina, cervix and uterus and its cyclic variation. Am. J. Obstet. Gynecol., 104:508-516.

Adler, N.T., J.A. Resko, and R.W. Goy 1970 The effect of copulatory behavior on hormonal change in the female rat prior to implantation. Physiol. Behav., 5:1003-1007.

Allen, J.M., J.C. Yeats, M.A. Blank, G.P. McGregor, J. Gu, J.M. Polak, and S.R. Bloom 1985 Effect of 6-hydroxydopamine on neuropeptides in the rat female genitourinary tract. Peptides, 6:12131217

Alm, P., J. Almuts, R. Hakånson, C. Owman, N.-O. Sjöberg, F. Sundler, and B. Walles 1980 Origin and distribution of VIP (vasoactive intestinal polypeptide) nerves in the genito-urinary tract. Cell Tiss. Res., 205:337-347.

Anderson, C.R. and E.M. McLachlan 1991 The time course of the development of the sympathetic innervation of the vasculature of the rat tail. J. Auton. Nerv. Syst., 35:117-132.

Baker, H.A., J.P. Burke, R.K. Bhatnagar, D.E. VanOrden, L.S. VanOrden, III, and B.K. Hartman 1977 Histochemical and biochemical characterization of the rat paracervical ganglion. Brain Res. 132:393-405.

Baljet, B. and J. Drukker 1980 The extrinsic innervation of the pelvic organs in the female rat. Acta Anat., 107:241-267.

Blessing, W.W., P.R.C. Howe, T.H. Joh, J.R. Oliver, and J.O Willoughby 1986 Distribution of tyrosine hydroxylase and neuropeptide Y-like immunoreactive neurons in rabbit medulla oblongata, with attention to colocalization studies, presumptive adrenaline-synthesizing perikarya and vagal preganglionic cells. J. Comp. Neurol., 248:285-300.

Brauer, M.M., J. Lincoln, D. Blundell, and A. Corbacho 1992 Postnatal development of noradrenaline-containing nerves of the rat uterus. J. Auton. Nerv. Syst., 39:37-50.

Carlson, R.R. and V.J. DeFeo 1965 Role of the pelvic nerve vs the abdominal sympathetic nerves in the reproductive function of the female rat. Endocrinology, 77:1014-1022.

Cunningham, S.T., J.S. Rosenblatt, and B.R. Komisaruk 1992 Reflexive ovulation in the rat, induced by Cesarean section, is blocked by pelvic and/or hypogastric nerve transection. Neuroendocrinology, 56:393-396.

Dail, W.G., Jr., A.P. Evan, and H.R. Eason 1975 The major ganglion in the pelvic plexus of the male rat. A histochemical and ultrastructural study. Cell Tiss. Res., 159:49-62.

Dohler, K.D. and W. Wuttke 1975 Changes with age in levels of serum gonadotropins prolactin and gonadal steroids in prepubertal male and female rats. Endocrinology, 97:898-907.

El-Badawi, A. and E.A. Schenk 1967 Histochemical methods for separate, consecutive and simultaneous demonstration of acetylcholinesterase and norepinephrine in cryostat sections. J. Histochem. Cytochem., 15:580-588.

Furness, J.B., M. Costa, and J.H. Walsh 1981 Evidence for and significance of the projection of VIP neurons form the myenteric plexus to the taenia coli in the guinea pig. Gastroenterology, 80:1557-1561

Gainer, H., Y.P. Loh, and Y. Sarne 1977 Biosynthesis of neuronal peptides. In: Peptides in Neurobiology. Plenum Press, New York pp. $180-213$

Gibbins, I.L., L.B. Furness, and M. Costa 1987 Pathway-specific patterns of the co-existence of substance $P$, calcitonin gene-related peptide, choleycystokinin and dynorphin in neurons of the dorsal root ganglia of the guinea-pig. Cell Tiss. Res., 248:417-437.

Greenwood, D. and R.E. Coggeshall 1985 Sexual dimorphism in the numbers of neurons in the pelvic ganglia of adult rats. Brain Res., 340:160-162.

Gu, J., J.M. Polak, H.C. Su, M.A. Blank, J.F.B. Morrison, and S.R. Bloom 1984 Demonstration of paracervical ganglion origin for the vasoactive intestinal polypeptide-containing nerves of the rat uterus using retrograde tracing techniques combined with immunocytochemistry and denervation procedures. Neurosci. Lett., 51 : $377-382$

Hall, A.K. and S.C. Landis 1991a Principal neurons and small intensely fluorescent (SIF) cells in the rat superior cervical ganglion have distinct developmental histories. J. Neurosci., 11:472 484 .

Hall, A.K. and S.C. Landis $1991 \mathrm{~b}$ Early commitment of precursor cells from the rat superior cervical ganglion to neuronal or non-neuronal fates. Neuron, 6:741-752.

Hervonen, A., L. Kanerva, and R. Lietzen 1973 Histochemically demonstrable catecholamines and cholinesterases of the rat uterus during estrus cycle, pregnancy and after estrogen treatment. Acta Physiol. Scand., 87:283-288.

Heym, C., M. Reinecke, E. Weihe, and W.G. Forssmann 1984 Dopamine-B-hydroxylase-, neurotensin-, substance P-, vasoactive intestinal polypeptide- and enkephalin-immunohistochemistry of paravertebral and prevertebral ganglia in the cat. Cell Tiss. Res., 235:411-418.

Hill, C.E., R.S.G. Jones, G.D.S. Hirst, and F.R. Edwards 1991 Development of a functional innervation of the iris dilator muscle by sympathetic nerve fibers in the rat. J. Auton. Nerv. Syst., 32:2130 .

Inyama, C.O., G.W. Hacker, J. Gu, D. Dahl, S.R. Bloom, and J.M. Polak 1985 Cytochemical relationships in the paracervical ganglion (Frankenhauser) of rat studied by immunohistochemistry. Neurosci. Lett., 55:311-316

Kanerva, L. 1971 The postnatal development of monoamines and cholinesterases in the paracervical ganglion of the rat uterus. In: Histochemistry of Nervous Transmission. O. Eranko, ed. Elsevier, Amsterdam, pp. 433-443.

Kanerva, I. 1972a Ultrastructure of sympathetic ganglion cells and granule-containing cells in the paracervical (Frankenhauser) ganglion of the newborn rat. Z. Zellforsch., 126:25-40.

Kanerva, L. 1972b Light and electron microscopic observations on the postnatal development of the rat paracervical (Frankenhauser) ganglion. Z. Anat. Enwicklungsgesch., 136:33-50.

Kanerva, L. and H. Teravainen 1972 Electron microscopy of the paracervical (Frankenhauser) ganglion of the adult rat. $Z$. Zellforsch. Mikrosk. Anat., 129:161-177.

Keast, J.R. 1992 Location and peptide content of pelvic neurons supplying the muscle and lamina propria of the rat vas deferens. J. Auton. Nerv. Syst., 40:1-12.

Langworthy, O.R. 1966 Innervation of the pelvic organs of the rat Invest. Urol., 2:491-511.

Lundberg, J.M., T. Hökfelt, A. Anggard, L. Terenius, R. Elde, K. Markey, M. Goldstein, and K. Kimmel 1982a Organizational principles in the peripheral sympathetic nervous system: Subdivision by coexisting peptides (somatostatin-, avian pancreatic peptide-, and vasoactive intestinal polypeptide-like immunoreactive materials). Proc. Natl. Acad. Sci. U.S.A., 79:1303-1307.

Lundberg, J.M., L. Terenius, T. Hökfelt, C.R. Martling, K. Tatemoto, V. Mutt, J. Polak, S. Bloom, and M. Goldstein 1982b Neuropeptide Y (NPY)-like immunoreactivity in peripheral noradrenergic neurons and effects of NPY on sympathetic function. Acta Physiol. Scand. 116:477-480

Lundberg, J.M., L. Terenius, T. Hökfelt, and M. Goldstein 1983 High levels of neuropeptide $\mathrm{Y}$ in peripheral noradrenergic neurons in various mammals including man. Neurosci. Lett., 42:167-172.

Molenaar, W.M., V.M.-Y. Lee, and J.Q. Trojanowski 1990 Early fetal acquisition of the chromaffin and neuronal immunophenotype by human adrenal medullary cells: An immunohistochemical study using monoclonal antibodies to chromogranin A, synaptophysin, tyrosine hydroxylase and neuronal cytoskeletal proteins. Exp. Neurol., 108:1-9.

Morris, J.L. and I.L. Gibbins 1987 Neuronal co-localization of peptides, catecholamines and catecholamine-synthesizing enzymes in guinea pig paracervical ganglion. J. Neurosci., 7:3117-3130.

Mustonen, T. and H. Teravainen 1971 Synaptic connections of the paracervical (Frankenhauser) ganglion of the rat uterus examined with the electron microscope after division of the sympathetic and sacral parasympathetic nerves. Acta Physiol. Scand., $82: 264-267$ 
Nadelhaft, I. and A.M. Booth 1984 The location and morphology of preganglionic neurons and the distribution of visceral afferents from the rat pelvic nerve: A HRP study. J. Comp. Neurol., 226: $238-245$.

Nadelhaft, I. and P.L. Vera 1991 Neurons labeled after the application of tracer to the distal stump of the transected hypogastric nerve in the rat. J. Auton. Nerv. Syst., 36:87-96.

Ojeda, S.R., P.S. Kalra, and S.M. McCann 1975 Further studies on the maturation of the estrogen negative feedback on gonadotropin release in the female rat. Neuroendocrinol., 18:242-255.

Ottesen, B., J.-J. Larsen, J. Fahrenkrug, M. Stjernquist, and F. Sundler 1981 Distribution and motor effect of VIP in female genital tract. Am. J. Physiol., 240:E32-E36.

Papka, R.E. 1972 Ultrastructural and fluorescence histochemical studies of developing sympathetic ganglia in rabbit. Am. J. Anat. 134:337-363.

Papka, R.E. 1976 Studies of cardiac ganglia in pre- and postnatal rabbits. Cell Tiss. Res., 175:17-35.

Papka, R.E., J.P. Cotton, and H.H. Traurig 1985 Comparative distribution of neuropeptide $\mathrm{Y}$-, vasoactive intestinal polypeptide-, substance $\mathbf{P}$-immunoreactive, acetylcholinesterase-positive and noradrenaline nerves in the reproductive tract of the female rat. Cell Tiss. Res., 242:4775-4490.

Papka, R.E. and D.L. McNeill 1992 Coexistence of calcitonin generelated peptide and galanin immunoreactivity in female rat pelvic and lumbosacral dorsal root ganglia. Peptides, 13:761-767.

Papka, R.E. and H.H. Traurig 1988 Distribution of subgroups of neuropeptide $\mathrm{Y}$-immunoreactive and noradrenergic nerves in the female rat uterine cervix. Cell Tiss. Res., 252:533-541.

Papka, R.E. and H.H. Traurig 1993 Autonomic and visceral sensory innervation of the female reproductive system: Special reference to neurochemical markers in nerves and ganglionic connections. In: Nervous Control of the Urogenital System. C.A. Maggi, ed. Harwood Academic, pp. 421-464.

Papka, R.E., H.H. Traurig, and P. Klenn 1987 Paracervical ganglia of the female rat: Histochemistry and immunohistochemistry of neurons, SIF celis and nerve terminals. Am. J. Anat., 179:243257.

Partanen, M. and A. Hervonen 1979 The formaldehyde-induced fluorescence of the developing hypogastric (main pelvic) ganglion of the rat: Short adrenergic neurons and the effect of testosterone. Histochemistry, $62: 249-258$.

Partanen, M., A. Hervonen, and H. Alho 1980 Microspectrofluorimetric estimation of the formaldehyde-induced fluorescence of the developing main pelvic ganglion of the rat. Histochem. J., 12:4956.

Purinton, P.T., T.F. Fletcher, and W.E. Bradley 1973 Gross and light microscopic features of the pelvic plexus in the rat. Anat. Rec., 175:697-706

Sato, S., R.H. Hayashi, and R.E. Garfield 1989 Mechanical responses of the rat uterus, cervix and bladder to stimulation of the hypogastric and pelvic nerves in vivo. Biol. Reprod., 40:209-219.

Shabanah, E.H., A. Toth, and G.B. Maughan 1964a The role of the autonomic nervous system in uterine contractility and blood flow. 1. The interaction between neurohormones and sex steroids in the intact and isolated uterus. Am. J. Obstet. Gynecol., 89: $841-859$.

Shabanah, E.H., A. Toth, and G.B. Maughan $1964 \mathrm{~b}$ The role of the autonomic nervous system in uterine contractility and blood flow. Am. J. Obstet. Gynecol., 89:860-880.

Steiner, D.F., K. Docherty, and R. Carroll 1984 Golgi/granule processing of peptide hormone and neuropeptide precursors: A minireview. J. Cell. Biochem., 24:121-130.

Stephanini, N., C. DeMartino, and L. Zamboni 1967 Fixation of ejaculated spermatozoa for electron microscopy. Nature, 216:173174.

Stjernquist, M. and C. Owman 1984 Vasoactive intestinal polypeptide (VIP) inhibits neurally evoked smooth muscle activity of rat uterine cervix in vitro. Reg. Peptides, 8:161-176.

Stjernquist, M., P. Emson, C. Owman, N.-O. Sjöberg, F. Sundler, and $K$. Tatemoto 1983 Neuropeptide $Y$ in the female reproductive tract of the rat. Distribution of nerve fibers and motor effects. Neurosci. Lett., 39:279-284.

Stjernquist, M., P. Alm, R. Ekman, C. Owman, N.-O. Sjöberg, and F. Sundler 1985 Levels of neural vasoactive intestinal polypeptide in rat uterus are markedly changed in association with pregnancy as shown by immunocytochemistry and radioimmunoassay. Biol. Repro., 33:157-163.

Takahashi, O. 1960 On the formation of vacuoles in the nerve cells of the ganglion cervicalis uteri of the rat and mouse. Okajimas Folia Anat. Japonica, 34:189-205.

Takahashi, O. and K. Shimai 1961 Study on the ganglion cervicalis uteri of the aged rats. Okajimas folia Anat. Japonica, 36:455465.

Traurig, H., A. Saria, and F. Lembeck 1984 The effects of neonatal capsaicin treatment on the growth of subsequent reproductive function in the rat. N-S Arch. Pharm., 327:254-259.

Wadhwas, S., G. Jotwani, and A. Balasubramaniam 1993 Development of neuropeptide Y-like immunoreactivity in the rat heart. Acta Histochem. Cytochem., 26:227-231.

Weisz, J. and P. Gunsalus 1973 Estrogen levels in immature female rats: True or spurious-ovarian or adrenal. Endocrinology, 93: $1057-1065$. 